\title{
On Improving Full-time Professional Degree Postgraduate Training Quality of Control Engineering
}

\author{
Wei-Jian Ren ${ }^{1, a}$, Yan-Qin Wang ${ }^{1,2, b,{ }^{*}, \text { Hong-Li Dong }}{ }^{1, c}$, Feng-Cai Huo ${ }^{1, d}$, \\ Chao-Hai Kang ${ }^{1, \mathrm{e}}$ \\ ${ }^{1}$ Electrical and Information Engineering Institute, Northeast Petroleum University, China \\ ${ }^{2}$ Mechanical and Electrical Engineering School, Daqing Normal University, China \\ arenwj@126.com, 'byqdqpi@126.com, 'chiningdhl@gmail.com, 'huofengcai@126.com, \\ e1440976@qq.com \\ ${ }^{*}$ Corresponding author
}

Keywords: Full-time professional degree, Postgraduate education, Professional practice.

\begin{abstract}
With the rapid development of economics in our country, a large number of high-level specialized talents are needed. From 2009 universities expand the enrollment scope to recruit this year's undergraduates to professional degree postgraduates study in our country. In order to improve the training quality of control engineering full-time professional degree postgraduate, a series of reforms are carried out in Northeast Petroleum University, our experience and practice is represented.
\end{abstract}

\section{Introduction}

Full-time professional degree is a kind of degree that cultivate high-level talents who have strong professional ability and quality, and can creatively be engaged in practical work to meet the needs of certain social specific professional fields[1,2]. Professional degree postgraduate education was carried out in our country since 1984. After 30 years' development, professional degree postgraduate education has developed rapidly. It can be divided into three stages, namely exploration period (1984-1989), beginning period (1990-2008) and reform period (since 2009). In 2009, the National Medium and Long-term Program for Education Reform and Development put forward clear requirements, to speed up the development of professional degree postgraduate education; universities began to enroll this year's undergraduates to professional degree postgraduates study in our country. Professional degree postgraduate education has entered a new development stage.

Regarding our country Some Opinions on Doing Well the Full-time Professional Degree Postgraduate Training Work by the Ministry of education clearly pointed out that we must establish reasonable position of professional degree postgraduate education, research deeper and accurately, grasp the rule of professional degree postgraduate education, innovate training idea, reform education mode, ensure training quality. Since the Opinion issued, colleges and universities actively explore and practice, and has obtained certain achievements in training full-time professional degree postgraduates, but still not reach the expected goals. In the case of professional degree postgraduate number increase rapidly, improving training quality of full-time professional degree postgraduate is the most urgent task of postgraduate education [3].

In order to cultivate control engineering talents that are equipped with innovation spirit and practice ability, we explore the training mode of full-time professional degree postgraduate education in Northeast Petroleum University based on the specialty experiment platform and practice base. In the training of full-time professional degree postgraduate, postgraduate students are the center of teaching. By means of highlighting and strengthening speciality practice, practical and exploratory case teaching, enterprise projects and graduation designs from the practical application problems are taken as the carrier, effective process control and excellent teacher team are the guarantee of talents training. Engineering practice ability and innovation ability are highlighted in full-time professional degree postgraduate education, they should grasp the 
professional solid basic theory and wide professional knowledge, has strong ability to solve practical problems and undertake professional technical or management work, become a high-level specialized talents with good professional quality [4].

\section{Optimize the Curriculum, Improve Teaching Methods}

The target of full-time professional degree postgraduate education is to cultivate high-level specialized talents with good practice ability, so its practice teaching is very important in the curriculum [5,6]. Practical application and professional requirements is the guidance of the curriculum and the improvement of comprehensive quality and application skills is the core, so that the practical ability of postgraduates can have significant improvement. Therefore, while making a full-time professional degree postgraduate training plan, we not only pay attention to the difference between academic postgraduate and professional degree postgraduate, but also distinguish the difference between engineering master and professional degree postgraduate. Increase practice hours and credits, and ensure that practice teaching can be carried out smoothly. Establish some courses that focus on improving students' ability in practical work and engineering application.

Teaching content of professional degree postgraduate emphasizes the combination of theory and application. Team learning, case analysis, field survey, simulation training etc. are used in teaching process. Emphasis is laid on cultivating postgraduates' consciousness and ability of solving practical problems, increasing their practical work experience, and improving their professional quality. Maintain the openness of course system to a certain degree, especially the professional elective courses, should be added or decreased according to the country's major needs to keep pace with the times. Postgraduates are encouraged to break the barrier of the discipline when choosing subject, interdisciplinary research on cross engineering practical problem [7]. The postgraduates are encouraged to participate in the activities of all kinds of competition and technological innovation of science and technology.

\section{Implement Professional Practice, Strengthen Production-Study-Research Cooperation}

Some stable research directions with professional and industry characteristics have been formed, such as oil storage and transportation process intelligent control, oilfield surface pipeline network system optimization theory and application, oilfield development predictive control, pattern recognition and artificial intelligence, nonlinear system identification and control forecast, intelligent information processing, production logging method and technology. We have won more than 20 items of national and provincial science and technology award. Some of the research results are at the international advanced level. These provide good condition for practice ability training of control engineering professional degree postgraduates. More than $85 \%$ postgraduate design topics are from the cooperation with enterprises and factories, ensure that students are close to actual production. Postgraduates' participating in enterprise project makes them really involve in the engineering problems, understand the industry background and study professional technology through participating in the technology development of actual projects in the above fields.

Special funds have been set up for the full-time professional degree postgraduate practice teaching. Based on the provincial key disciplines Control Theory and Control Engineering and provincial key lab Oil-gas Information and Control Engineering, control engineering major has a large number of high level experimental equipment, such as 3D inverted pendulum control system, three-dimensional automatic garage simulation system, multi-sensory robot system, DSP $\backslash$ ARM system, advanced process control system, soccer robot, integrated intelligent test system platform, intelligent instrument, PLC etc. The advanced experimental environment can meet the needs of practical ability training of professional degree postgraduate.

One of the effective ways of training engineering practice ability is production-study-research cooperation. Production-study-research cooperation means that, the production units, universities and research units cooperate with each other and play their respective advantages to cultivate high-level technical personnel that enterprises need indeed. Production-study-research cooperation 
is important measure deepen and guarantee the postgraduate education, especially the professional degree postgraduate education. Production-study-research, the key is to promote the real fusion between colleges and enterprises, around the major core technology, realize the concentration of three kinds of talent i.e. school teachers, postgraduate high-level talent team and enterprise technical expert team, and promote technological innovation. Universities make full use of social resources, and fully realize the value of their talent resources and technological results, thus realize the seamless connection between universities and enterprises, and create a broader space for cultivating high-level engineering talents.

Control engineering major has established good university-enterprise cooperation mechanism with oil companies, research institutes and other relevant departments and owns a provincial-level postgraduate university-enterprise Research and development Center. We are closely linked with enterprises in Daqing, and actively develop university-enterprise cooperation. Control engineering major has a provincial university-enterprise research and development center. Now we have established more than 10 close off-campus practice bases, which provide convenient conditions for us to realize production-study-research cooperation. By means of production-study-research cooperation we established Oil Production Process Optimization Control Technology Research and Development Centers". We now have 8 state-level scientific research projects, 14 provincial projects, more than 30 technology development projects which serve Daqing. More than $80 \%$ of the scientific research projects are from the petroleum and petrochemical enterprises.

\section{Construction of Teaching Staff, Implement Double-Teachers Accountability}

University teachers have profound theoretical knowledge and rich guiding experience, but not very familiar with the special background of enterprises in all sectors and the practical problems, so they are mainly responsible for the academic guidance, and focus on the scientific exploration spirit guiding of postgraduates. Tutors in enterprises have long been engaged in the practical work, and have deep understanding of the technology problems. They are responsible for the training of engineering practice ability of postgraduate students. To highlight the status and role of tutors in enterprises, strengthen the engineering practice part. The double-teachers accountability can play their respective advantages of university teacher and enterprise teacher; it can more comprehensively enhance the research and practical application ability of postgraduates.

Increase the proportion of teachers who have experience in enterprises or research institutes. When recruit professional teachers, give priority to those high level talents who have engineering experience. Through participating in enterprise engineering project or research and development projects, teachers obtain more abundant experience of engineering practice. At present, $40 \%$ of the professional teachers are with engineering or research and development experience. Encourage those who have innovation ability and innovation consciousness in enterprises and research institutes to teach in colleges and universities. Relying on Daqing oil field co., LTD and Daqing petroleum administration bureau, senior engineering and technical personnel are hired as enterprise teachers to run relative courses and guide students internship and practice, graduation designing etc. They also carry out lectures $t$ has rich contents and various forms, and practical courses for underpostgraduates regularly.

\section{Improve Process Monitoring System and Evaluation Mechanism}

Establishing a sound management system is one of the most urgent tasks of full-time professional degree training work, strictly implement standardized management, make clear training requirements and regulate training process in accordance with institution. Process management requires equal attention with objective management. Grasp every aspect of course study, professional practice and master's degree thesis. For a long time, in the training evaluation system, emphasis of training quality monitoring and evaluation is mainly laid on the academic requirement and quantitative monitoring and evaluation of practical application ability is less, this constrained the training quality improvement of full-time professional degree postgraduate. The establishment of evaluation system 
for control engineering full-time postgraduates is based on scientificity, purpose, maneuverability and rationality. It effectively strengthens the macro management and guidance of practical ability and engineering ability training, scientifically evaluates teaching effect, improves the practice teaching system, and promotes teaching quality of professional degree postgraduates.

\section{Acknowledgement}

This research is supported by the National Engineering Professional Degree Postgraduate Education Optional Research Topic (No. 2014-JY-042) and Teaching reform project of Education Department in Heilongjiang Province (JG2014010636).

\section{References}

[1] Galloway P.D. The 21st-century engineer: A proposal for engineering education reform, Civil Engineering-ASCE, 77(2007) 46-57, 98-104.

[2] Shan X, Gong Z, Xu J, The history inevitability of the full-time professional degree graduate education development. Chin High Educ Res, 11(2010) 34-37.

[3] Chunjun Zhu, Research on quality of full-time professional degree postgraduate education, Informatics and Management Science I, 204(2013) 593-599.

[4] Stiwnea E.E. Jungerta T. Engineering students' experiences of transition from study to work, Journal of Education and Work, 23(2010) 417-437.

[5] HEITMANNA G, Challenges of engineering education and curriculum development in the context of the Bologna process, European Journal of Engineering Education, 30(2005) 447-458.

[6] Gavin K G, Design of the curriculum for a second-cycle course in civil engineering in the context of the Bologna framework, European Journal of Engineering Education, 35(2010) 175-185. [7] Ertas A, Maxwess T, Rainey V P, Tanik M M, Transformation of higher education: The transdisciplinary approach in engineering, IEEE Transactions on Education, 46(2003) 289-295. 